\title{
Delayed Seizures Occurring with Hypoxic- Ischemic Encephalopathy in the Fetal Sheep
}

\author{
CHRIS E. WILLIAMS, ALISTAIR J. GUNN, BETH SYNEK, AND PETER D. GLUCKMAN \\ Developmental Physiology [C.E.W., A.J.G., P.D.G.J, and Department of Paediatrics and Pathology [B.S.], \\ University of Auckland, Auckland, New Zealand
}

\begin{abstract}
The pathogenesis of perinatal hypoxic-ischemic encephalopathy is poorly understood. Most insults are thought to occur before or during birth. We have investigated the evolution of parasagittal EEG activity and distribution of neuronal damage after cerebral ischemia in chronically instrumented fetal sheep (119-126 d gestation). The vertebral-carotid anastomoses were ligated and cerebral ischemia was induced by inflating occluder cuffs around the carotid arteries for $\mathbf{3 0} \mathrm{min}$. Parietal cortical EEG activity was analyzed with real-time spectral analysis with reference to control fetuses. After ischemia, EEG activity was suppressed, then rapidly increased in intensity at $8 \pm 1 \mathrm{~h}$ to a peak at $9 \pm 1 \mathrm{~h}$ postischemia. There was increased intensity of the lower frequencies (1-7 Hz) apparent as epileptiform activity with convulsions. This lowfrequency hyperactivity gradually resolved by $28 \pm 7 \mathrm{~h}$ postinsult. After $72 \mathrm{~h}$, the loss of intensity at all frequencies and laminar necrosis of the underlying parasagittal cortex indicated irreversible brain injury. Ranking the structures in order of decreasing amounts of damage: parasagittal cortex $>$ hippocampal CA1, 2, and 3 regions $>$ lateral cortex, hippocampal CA4 region and striatum $>$ amygdala, dentate gyrus, thalamus, and cerebellum. The evolution of EEG activity and the distribution of damage after cerebral ischemia closely resembles the time course and pathology of hypoxic-ischemic encephalopathy seen in some severely asphyxiated term neonates. The consistent electrophysiologic and histologic outcome should allow this experimental approach to be valuable in testing a number of current hypotheses relating to perinatal asphyxial encephalopathy. (Pediatr Res 27: 561-565, 1990)
\end{abstract}

\section{Abbreviations}

HIE, hypoxic-ischemic encephalopathy EMG, electromyographic

The clinical signs of neonatal HIE are well known. Seizures after severe asphyxia in the neonate are frequently associated with poor neurologic outcome (1), often with indications of damage to the parasagittal cerebral cortex (2). Little is known about the pathophysiology and genesis of this characteristic pattern of brain damage. Several authors have speculated that postinsult epileptiform activity worsens neurologic outcome (3, $4,5)$; however, an appropriate preparation has not been described that will enable this hypothesis to be tested in the developing or

Received July 25, 1989; accepted February 2, 1990

Correspondence and reprint requests: Chris E. Williams, Developmental Physiology, Department of Paediatrics, University of Auckland, Private Bag, Auckland, New Zealand.

Supported by grants from the Medical Research Council of New Zealand and the Wellcome Trust. mature brain $(6,7)$. Most asphyxic insults occur in the fetus as antepartum or intrapartum events $(8-10)$. Thus, to start to investigate aspects of the pathophysiology of HIE, we have examined the evolution of parasagittal EEG activity and the pathologic outcome after cerebral ischemia in fetal sheep.

For our study, we have developed an experimental approach to induce cerebral ischemia in the chronically instrumented sheep fetus in a reproducible manner. The quantitative measurements of EEG activity were made using continuous real-time spectral analysis (11). This paper describes the sequential EEG changes with delayed onset of seizures and the pathologic outcome at $3 \mathrm{~d}$ postinsult. We discuss the relevance of the findings to HIE in human infants.

\section{MATERIALS AND METHODS}

Surgical procedures. Fourteen Romney/Suffolk fetal sheep of known gestational age were operated on under halothane anaesthesia $(2 \%)$ using sterile techniques. These surgeries took about $90 \mathrm{~min}$. The head, neck, and forelimbs of the fetus were externalized for an average of $60 \mathrm{~min}$. Catheters were inserted into each of the axillary arteries. Two pairs of shielded stainless steel electrodes were placed bilaterally on the parietal dura. These were inserted via parasagittal burr holes that were drilled in the skull overlying the parietal cortex (skull coordinates relative to Bregma: anterior $5 \mathrm{~mm}$ and $15 \mathrm{~mm}$, lateral $10 \mathrm{~mm}$ ). In addition, a pair of stainless steel wire electrodes (AS636 Cooner Wire Co., Chatsworth, CA) were sewn into the paraspinal nuchal muscle to record their activity (EMG). The vertebral-occipital anastomoses between the carotid arteries and vertebral arteries were ligated bilaterally. The vertebral arteries in the sheep do not supply the brain, but rejoin the common carotid arteries, while the basilar artery is supplied from the Circle of Willis (12). Thus, this procedure eliminates all collateral supply. Inflatable occluder cuffs were placed around both carotid arteries. The leads and catheters were externalized to the maternal flank and uterine and abdominal walls were closed. After the operation, the ewe was housed in a metabolic cage at constant temperature $\left(20^{\circ} \mathrm{C}\right)$ and humidity $(50 \%)$ and given free access to hay and water supplemented by sheep nuts and alfalfa. Antibiotics (penicillin and gentamicin) were administered to the ewe daily.

Recording. Movement artifacts in the EEG were minimized by using driven shield electrodes. These recording electrodes were constructed from shielded Teflon insulated wire (AS636 1SSF, Cooner Wire Co.). The signal was amplified 5000 times by instrumentation amplifier and preamplifier before filtering. Antialiasing filtering was accomplished with 8th order switched capacitor Butterworth filters, with the $-3 \mathrm{~dB}$ point set to $30 \mathrm{~Hz}$. All experiments were recorded on analog chart running at 5 $\mathrm{mm} / \mathrm{min}$. Intensity (power) spectra were obtained by real-time spectral analysis (11). The EEG was continuously sampled at $111 \mathrm{~Hz}$ and intensity spectra were analyzed from this data. These spectra were averaged over $5.5-\mathrm{min}$ intervals, and each average spectrum stored to disk. EMG activity was amplified by instru- 
mentation amplifier then bandpass filtered $100-1000 \mathrm{~Hz}$ before rectifying and lowpass filtering to produce an envelope of activity.

Experimental procedures. Experiments were started 72 to 96 $h$ after surgery. Fetuses ranged in gestational age from 119 to $126 \mathrm{~d}$. Fetal arterial samples were obtained before the start of each experiment and only fetuses exhibiting normal arterial blood gases $\left(\mathrm{pH}>7.32\right.$ and $\mathrm{PaO}_{2}>17 \mathrm{~mm} \mathrm{Hg}$ ) were used. After $4 \mathrm{~h}$ of collecting EEG spectral data (reference period), the carotid cuffs were inflated with saline for $30 \mathrm{~min}$. Spectra were then collected continuously for the next $32 \mathrm{~h}$. In addition, 4-h blocks of spectra were collected at 48 and $72 \mathrm{~h}$ postischemia. Because experience showed that about one-third of cuffs burst on inflation, we prospectively chose to use these as controls. Five animals were thus deemed controls and nine experimental animals. Two other animals were rejected from the EEG analyses due to technical failures of the EEG recording.

Each sheep was killed $3 \mathrm{~d}$ postinsult by pentobarbital infusion; the fetus was immediately removed and the brain perfused through the common carotid arteries with $500 \mathrm{~mL}$ normal saline followed by $500 \mathrm{~mL} 10 \%$ formalin, then $500 \mathrm{~mL} 10 \%$ formalin/ $10 \%$ sucrose. The brains were embedded in paraffin, coronally subserially sectioned to $10 \mu \mathrm{M}$, and then stained with thionin/ acid fuchsin (13). Every 40th section was mounted and examined by light microscopy. Each selected region was assessed under a magnification of $100 \times$ before detailed assessment at a magnification of $400 \times$. Neurons with ischemic cell change were identified according to the criteria of Brown and Brierley (14). Cells with acidophilic (red) cytoplasm and contracted nuclei or with just a thin rim of red cytoplasm with pyknotic nuclei were assessed as dead, whereas all others were considered viable. Each region was scored in multiple preselected areas for the proportion of dead neurons by two independent assessors. One of the assessors was blind to the experiment. The cortical regions were selected from sections of the temporo-parietal cortex corresponding with the positions of the EEG electrodes. "Parasagittal" cortex was taken to include all of the gyrus bordering the sagittal sulcus, and the medial half of the laterally adjacent gyrus. "Lateral" cortex included all of the most lateral gyrus on the section.

The average values from two sections and from both the right and left hemispheres were used in all cases except for the thalamii, where all the nuclei in three sections were used, and the hippocampus, where the dorsal and ventral gyri were also averaged. A 6-point damage scale was used. Each region was scored for damage as follows: $0,1-10 \%, 10-50 \%, 50-90 \%, 90-99 \%$, and $100 \%$ neurons dead. To enable statistics to be performed on this 6-point scale, the nominal damage score was taken as the midpoint of each of these ranges: $0,5,30,70,95$, and 100 , respectively. As these scores are on a ratio scale, comparisons of the degree of damage could be made using parametric statistical methods (15).

Analysis. Intensity spectra were obtained as previously described (11). The averaged spectra were segmented into seven frequency bands before further analysis. The $\delta$-band ranged from 1.25 to $4.50 \mathrm{~Hz}$, then $\theta$ to $6.75, \alpha$-I to $9.50, \alpha$-II to $12.50, \beta$-I to 18.50 , and $\beta$-II to 32 (16). The descriptive measurements and peak intensity and peak width (half ht) measurements were made on the smoothed time series. For smoothing, a digital Blackman (17) lowpass filter with a cutoff of 0.1 cycles/point was applied to the log-transformed data to minimize short-term fluctuations of less than 20 min. Peak measurements were made by a maxima detecting algorithm on both the control and ischemia fetuses.

For statistical analysis, all calculations were made on logarithms of the intensity of each frequency band. This transformation gives a better approximation to the normal distribution (18). Each log-transformed frequency band was normalized with respect to the mean value of the first $4 \mathrm{~h}$ of recording (16). This normalization removes variability in amplitude between animals that is a consequence of electrode positioning. After descriptive measurements were made, selected times in the experimental animals were compared with the control group using multivariate analysis of variance. Individual comparisons of frequency bands were then compared with $t$ tests with Tukey's correction for multiple comparisons. Changes with time were compared with repeated measures of analysis of variance. Similarly histologic damage scores were analyzed by analysis of variance, whereas ranking of damage was performed with the Waller-Duncan multiple comparisons test.

\section{RESULTS}

Thirty min of ischemia induced complete suppression of the parietal EEG during the insult, followed by a consistent sequence of changes in its intensity (Fig. 1$)(P<0.0001)$. Descriptive measurements suggested that the EEG intensity was suppressed until $8 \pm 1 \mathrm{~h}$ (mean \pm SEM), then rapidly reached a peak at $9 \pm$ $1 \mathrm{~h}$ with increased low-frequency $(1-5 \mathrm{~Hz})$ intensity. The highfrequency $(19-32 \mathrm{~Hz})$ intensity also peaked at $9 \pm 1 \mathrm{~h}$ for $2 \pm 1$ $\mathrm{h}$ (half ht width of peak). This low-frequency intensity then declined to below preinsult levels by $28 \pm 7 \mathrm{~h}$ postischemia. The increased low-frequency activity was apparent as spike-wave or polyspike activity on the raw EEG and occurred with increased nuchal muscle activity. The patterns of nuchal muscle activity
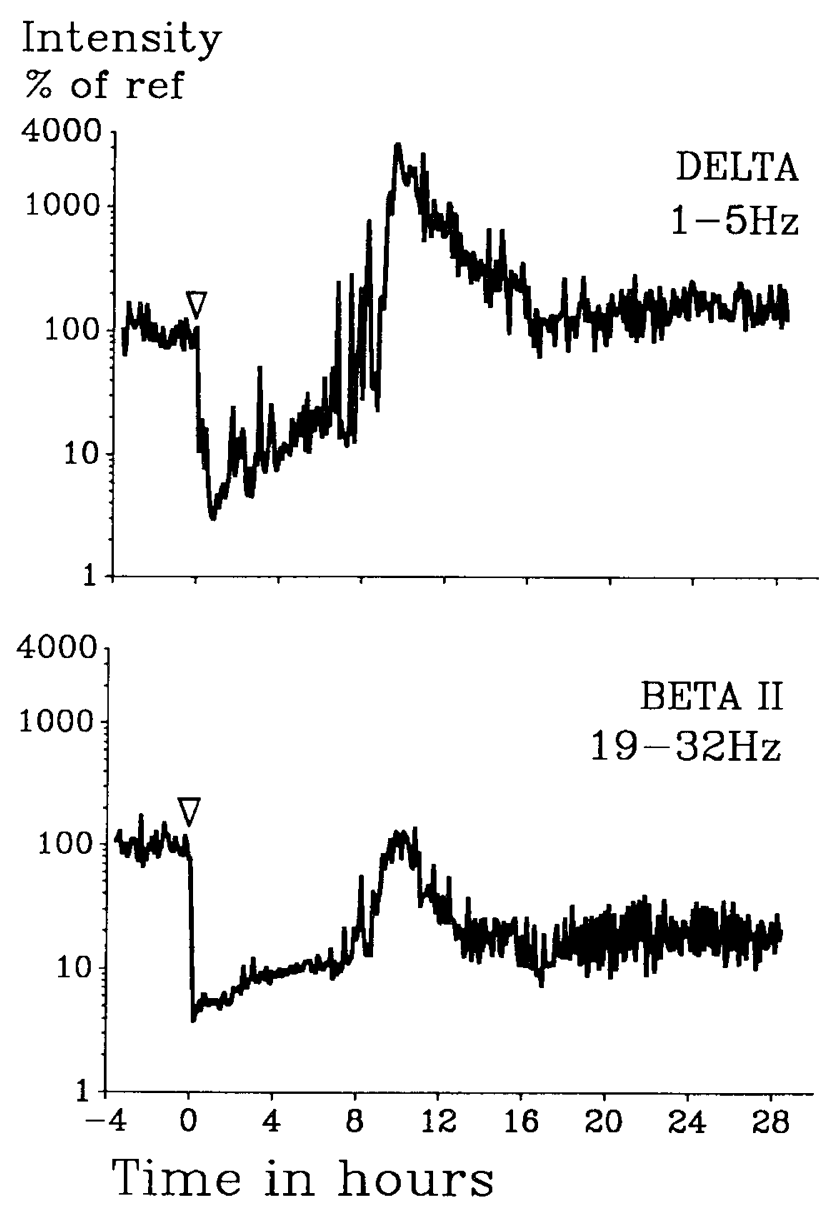

$\nabla 30 \mathrm{~min}$ Ischemia

Fig. 1. The evolution of the EEG intensity expressed as a percentage of preischemic reference intensity in the low-frequency $(1-5 \mathrm{~Hz}) \delta$-band and the high-frequency (19-32 Hz) $\beta$-II band for $4 \mathrm{~h}$ before and $28 \mathrm{~h}$ after $30 \mathrm{~min}$ of cerebral ischemia in a fetal sheep (121 d gestation), commencing at time 0 indicated by the arrow. There was suppressed activity for about $8 \mathrm{~h}$ postinsult, followed by a rapid increase in lowfrequency $(\delta)$ intensity (epileptiform activity). This increase in lowfrequency activity coincided with the onset of epileptiform activity and seizures. The low-frequency activity gradually subsided. The high-frequency $(\beta$-II) intensity showed a brief increase toward preinsult levels, then was lost. 
suggested that both clonic convulsions, where the EMG activity was synchronous with spike-wave activity (Fig. 2), and tonic convulsions, where tonic EMG activity occurred with periods of intense epileptiform activity, were present.

Intensity data were separated into three time intervals: $1-5 \mathrm{~h}$, $10-15 \mathrm{~h}$, and $72-74 \mathrm{~h}$ postischemia for quantitative analysis. At $1-5 \mathrm{~h}$ postischemia, the EEG was suppressed in all frequency bands (Fig. 3). All frequencies then increased in intensity from the 1 - to 5 -h period to the $10-$ to $15-\mathrm{h}$ period $(p<0.0001)$. During the 10- to 15 -h period, the lower frequency bands $\delta$ to $\theta$ $(1-7 \mathrm{~Hz})$ were significantly increased in intensity, whereas the higher frequencies were not significantly different from control levels (Fig. 3). All frequencies then fell in intensity from 10-15 $\mathrm{h}$ to $72 \mathrm{~h}(p<0.0001)$. At $72-74 \mathrm{~h}$, intensities at all frequencies were significantly reduced (Fig. 3). The peak intensities occurred at $9 \pm 1 \mathrm{~h}$ and showed increased intensity of the lower frequency bands $\delta$ to $\alpha$-I $(1-10 \mathrm{~Hz})$, whereas the higher frequencies $\alpha$-II to $\beta$-II $(10-32 \mathrm{~Hz})$ were not significantly different from control intensities.

Histologic comparisons were made between five sham control fetuses and nine fetuses subjected to $30 \mathrm{~min}$ of ischemia (Fig. 4). The controls had no damage, whereas the fetuses subjected to an ischemic insult showed widespread neuronal necrosis (Fig. 5). Damage was greatest in the parasagittal cortex where there was laminar necrosis. Ranking the structures in order of decreasing amounts of damage: The parasagittal cortex was most affected, followed by CA 3 and CA1, 2 of the hippocampus, then the lateral cortex, CA4 of the hippocampus and striatum, then the amygdala, dentate gyrus, thalamus, and cerebellum. The moderately damaged regions of cortex tended to greatest neuronal death in layer 3 , with lesser neuronal losses in layer 2 then laminae 4, 6, 1, and the least in layer 5. Neuronal damage was greater in the depths of the sulci compared with the gyrii.

\section{DISCUSSION}

Our experimental approach of cerebral ischemia in the developing brain has certain parallels to HIE in the term newborn, namely delayed onset of seizures and a parasagittal distribution of cortical neuronal injury $(19,20)$. This correspondence between experimental and clinical disorder supports the hypothesis that parasagittal HIE is of ischemic origin, resulting from a period of impaired cerebral perfusion $(21,22)$. With this preparation, a reproducible ischemic insult can be delivered to an unanesthetized stable animal without compromise of cardiovascular or respiratory status. The highly consistent electrophysiologic and histologic outcome should allow this experimental approach to be valuable in testing a number of current hypotheses relating to perinatal asphyxial encephalopathy.

We have found a consistent sequence of changes in the EEG after the cerebral ischemia (Fig. 1). There was initially a period of suppressed EEG activity lasting several hours then at about 8 $h$ postinsult there was a rapid increase in EEG intensity, partic-

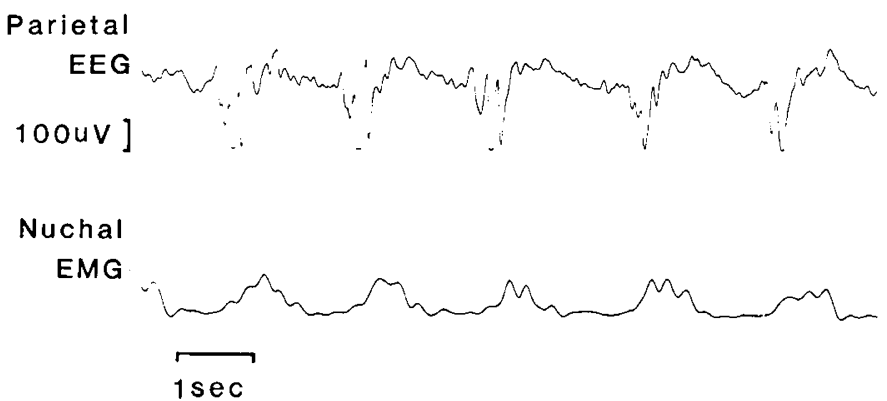

Fig. 2. Parietal EEG activity at $10 \mathrm{~h}$ postischemia, showing a lowfrequency spikewave pattern that is typical of epileptiform activity. The synchronous increases in the nuchal muscle activity indicate clonic convulsions.
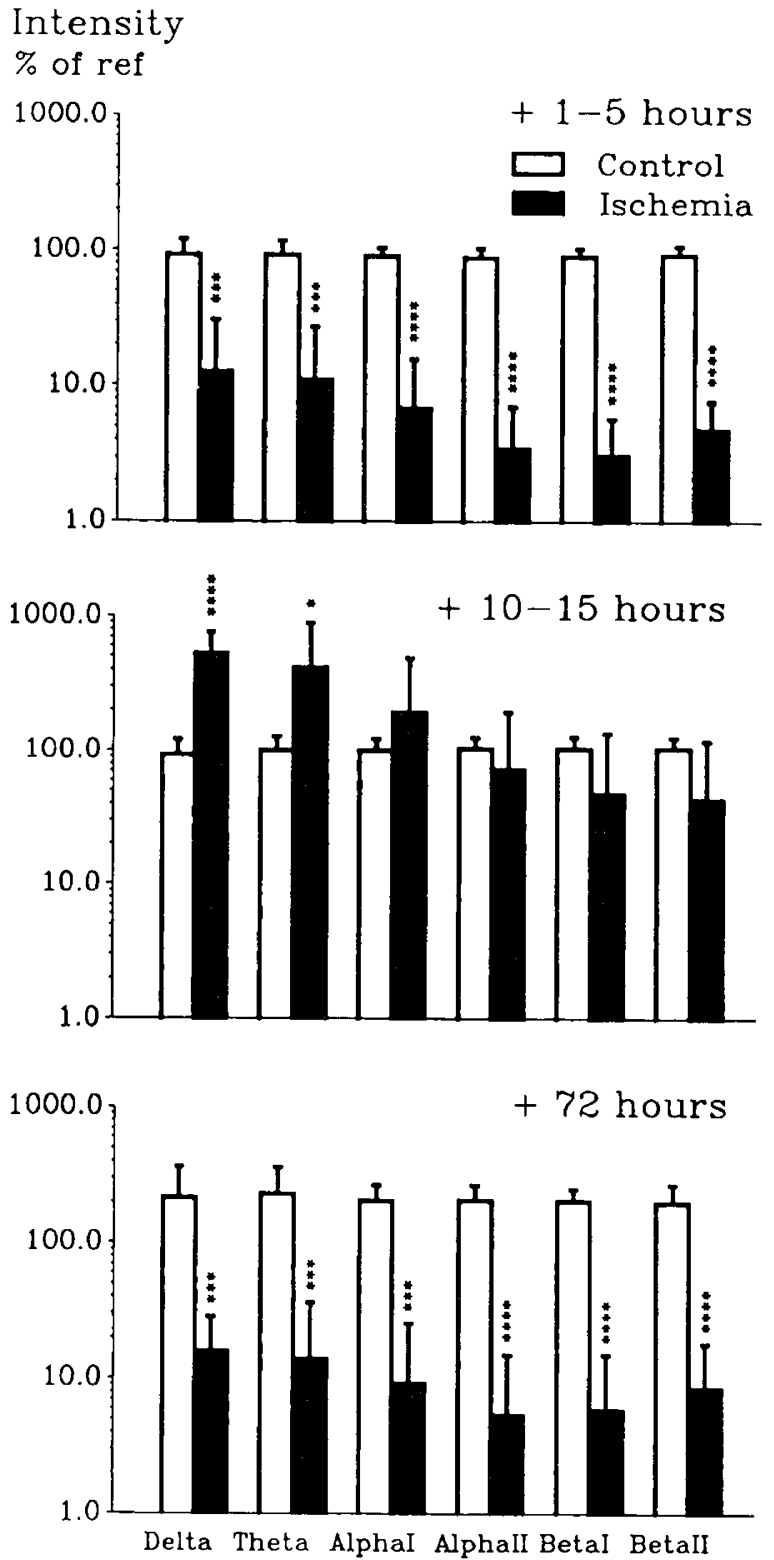

Fig. 3. The EEG intensity at 1-5, 10-15, and $72 \mathrm{~h}$ postischemia expressed as a percentage of the preischemic reference intensity. Intensity in each frequency band of the ischemia group $(n=7)$ was compared to the sham controls $(n=5)$. All frequencies were suppressed at $1-5 \mathrm{~h}$ postischemia, then low frequencies $\delta-\theta(1-7 \mathrm{~Hz})$ were increased at $10-$ $15 \mathrm{~h}$. At $72 \mathrm{~h}$, intensity of all frequencies was reduced. ${ }^{*}, p<0.05 ;{ }^{* *}, p$ $<0.01,{ }^{* * *}, p<0.001 ; * * * *, p<0.0001$.

ularly at the lower frequencies. The appearance of intense lowfrequency activity corresponded to the onset of spike-wave or polyspike (epileptiform) activity that was seen with EMG evidence of convulsions (Fig. 2). Similarly, delayed seizures are often observed in severely asphyxiated, full-term infants starting between 6 and $12 \mathrm{~h}$ after birth (8), and in asphyxiated newborn rhesus monkeys (23). The mechanisms leading to the delayed onset of seizure activity are not understood, and it remains controversial as to whether prevention of these seizures is associated with an improved outcome.

The distribution of cortical injury with predominant damage of the parasagittal cortex, particularly in the sulci, is typical of ischemic insults in humans (24). This distribution of damage has been observed after asphyxia in some term infants (2) and nonhuman primates (23). This distribution of damage corresponds to the arterial end fields in the border zones between the 


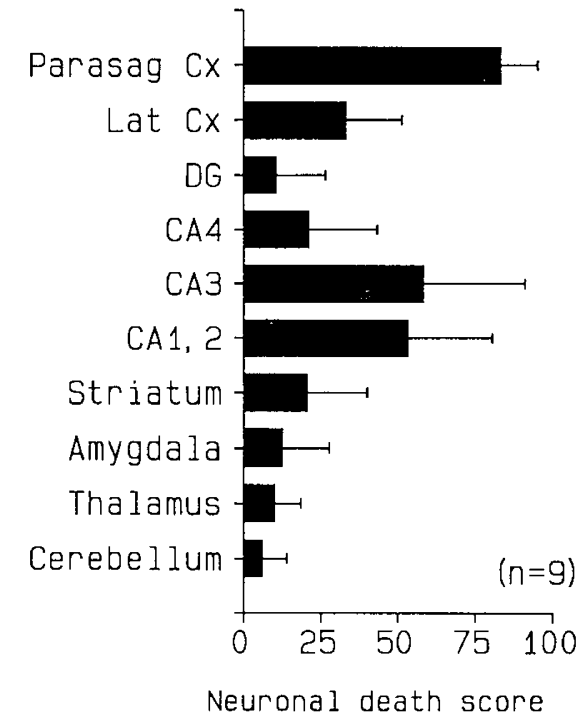

Fig. 4. Mean neuronal death scores from selected regions of the brains of nine fetal sheep subjected to $30 \mathrm{~min}$ of ischemia. Zero represents no neuronal loss and 100, total loss. Ranking the structures in order of decreasing susceptibility: parasagittal cortex (Parasag $C X$ ) $>$ CA 3 and CA $1,2>$ lateral cortex ( $L a t C x$ ), CA4 and striatum $>$ amygdala, dentate gyrus $(D G)$, thalamus, and cerebellum.

territories of the major cerebral arteries (anterior, middle, and posterior) (25). The relative sparing of diencephalic and metencephalic structures such as the cerebellum when compared with the cortex may reflect preferential perfusion of the residual flow to these structures as seen in neonatal rats, fetal sheep, and monkeys, and in newborn dogs and piglets during hypoxiaischemia or asphyxia (26-31). Alternatively, there may have been some anterograde flow through the basilar artery reversing the normal retrograde flow in the sheep (12).

Within the damaged regions of cortex there was heterogeneity of cell death, with laminar necrosis, particularly of pyramidal neurons situated in the lamina 3. This selective pattern of cell loss can occur after cerebral ischemia in adults (24) and has been observed in asphyxiated neonates (32). Vannucci et al. (26) have suggested that the ischemia determines the overall topography of damage, but metabolic factors influence the heterogeneous pattern of damage seen within regions. This pattern of selective neuronal necrosis may be excitotoxic damage from excessive activity of the excitatory amino receptors (33-35), although other factors such as local calcium accumulation and oxygen-free radicals may also play a role $(36,37)$ in the developing brain. Thus, this parasagittal topography and laminar pattern of damage is typical of ischemic insults and similar to that occurring in some asphyxiated term neonates.

The EEG potentials recorded from the cortex during epileptiform activity are generated by underlying pyramidal cells (38, 39). This epileptiform activity is associated with hyperactivity of these neurons (40). A similar sequence of hyperactivity followed by loss of activity occurs in the hippocampal neurons of Mongolian gerbils following an episode of ischemia (7). Selective neuronal death can occur after seizure activity in adult rats (41). Cell loss from seizure activity is thought to be a consequence of metabolic demands exceeding limited energy substrate availability in vulnerable neurons and not local hypoxia-ischemia (42). Thus, seizure activity can cause neuronal death, at least in adult animals. But it is not known to what extent the intense epileptiform activity contributes to the cell loss or is a manifestation of the pathogenesis in this preparation or in the clinical situation.

Normal cortical EEG activity is generated as a spatial summation of potentials from activity in the underlying pyramidal cells $(38,43,44)$. Thus, the intensity of the EEG reflects activity in the underlying pyramidal cells. The loss of intensity seen at

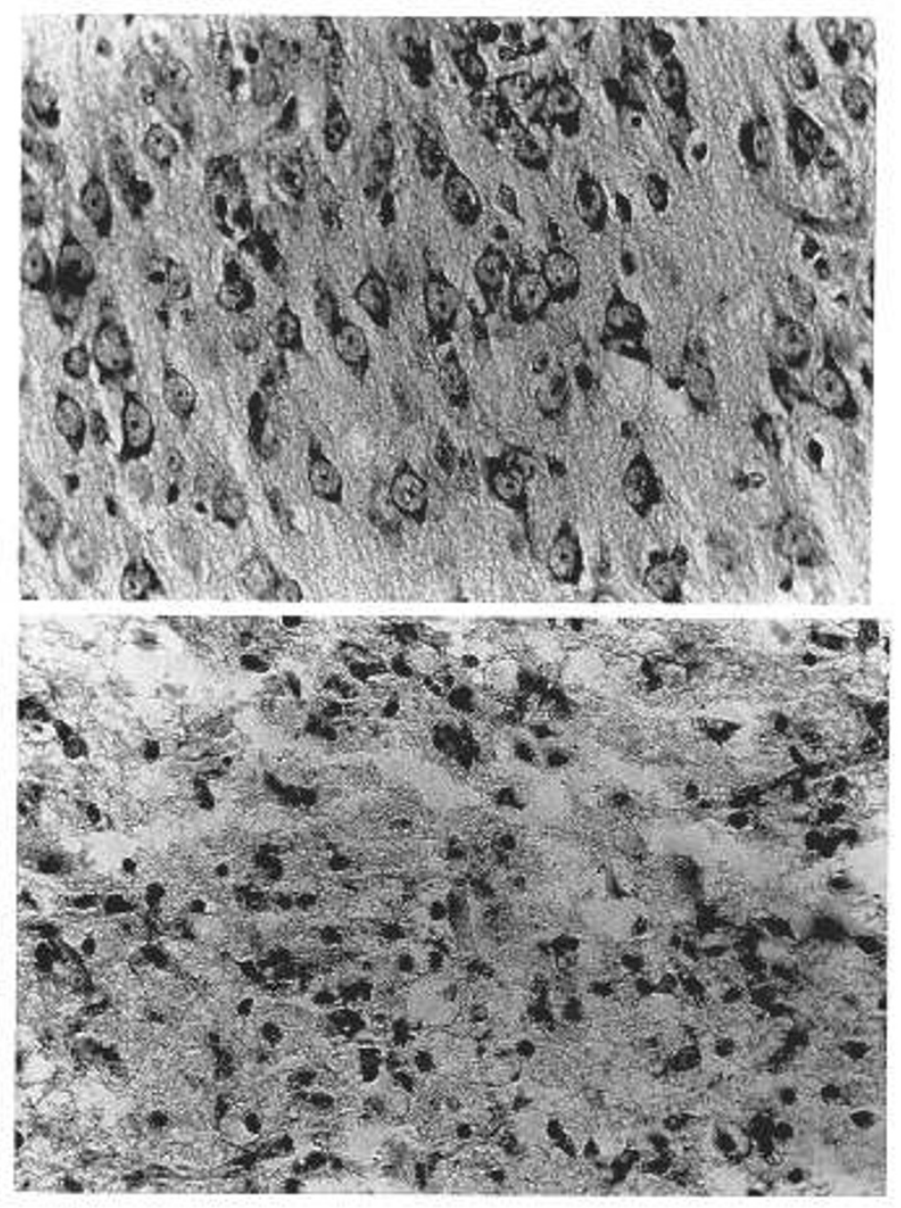

rig. ว. lllustrations or normal (upper panel) and severely damaged (lower panel) parietal cortex. Both are taken from the parasagittal region of the parietal cortex at a magnification of $400 \times$. The upper plate illustrates normal parietal cortex showing no neuronal loss and thus a damage score of 0 . The lower plate, from the same region $3 \mathrm{~d}$ after 30 min of ischemia, shows an area of total neuronal loss and was assigned a damage score of 100 .

$72 \mathrm{~h}$ postinsult probably reflects the loss of functional pyramidal cells apparent at that time.

These experiments have revealed a distinct sequence of suppressed, then increased EEG (epileptiform) activity culminating in loss of parasagittal cortical function after an ischemic insult. Despite our artificial approach, the genesis of EEG activity and distribution of damage closely resemble observations of HIE in some asphyxiated term neonates. The preparation we have developed, because of its reproducibility, may allow some hypotheses related to putative mechanisms and risk factors to be directly evaluated in the perinatal period.

Acknowledgment. The authors thank Karen Ball for her help.

\section{REFERENCES}

1. Mellits ED, Holden K, Freeman J 1982 Neonatal seizures. II. A multivariate analysis of factors associated with outcome. Pediatrics 70:177-185

2. Volpe JJ, Pasernak JF 1977 Parasagittal cerebral injury in neonatal hypoxicischemic injury. J Pediatr 91:472-476

3. Johansen F, Jorgensen M, Diemer N 1987 Ischemia induced delayed neuronal death in the CA-1 hippocampus is dependent on intact glutamatergic innervation. In: Hicks T, Lodge D, McLennan H (eds) Excitatory Amino Acid Transmission. Alan Liss, New York, 245-248

4. Brown A, Levy E, Kublik M 1979 Selective chromatolysis of neurons in the gerbil brain: a possible consequence of "epileptic" activity produced by common carotid artery occlusion. Ann Neurol 5:127-138

5. Meyer FB 1989 Calcium, neuronal hyperexcitability and ischemic injury. Brain Res Rev 14:227-243

6. Armstrong D, Neill K, Crain B, Nadler V 1989 Absence of electrographic seizures after transient forebrain ischemia in the Mongolian gerbil. Brain Res 476:174-178 
7. Suzuki R, Yamaguchi T, Choh-Luh L, Klatzo I 1983 The effects of 5-minute ischemia in Mongolian gerbils: II. Changes of spontaneous neuronal activity in cerebral cortex and CAl sector of hippocampus. Acta Neuropathol $60: 217-222$

8. Hill A, Volpe JJ 1981 Seizures, hypoxic-ischemic brain injury, and intraventricular haemorrhage in the newborn. Ann Neurol 10:109-121

9. Sheilds JR, Schifrin BS 1988 Perinatal antecedents of cerebral palsy. Obstet Gynecol 71:899-905

10. Low JA, Robertson DM, Simpson LL 1989 Temporal relationships of neuropathologic conditions caused by perinatal asphyxia. Am J Obstet Gynecol 160:608-614

11. Williams CE, Gluckman PD 1990 Real-time spectral intensity analysis of the EEG on a microcomputer. J Neurosci Methods (in press)

12. Baldwin BA, Bell F 1963 The anatomy of the cerebral circulation in the sheep and ox. The dynamic distribution of the blood supply by the carotid and vertebral arteries to cranial regions. $J$ Anat 97(2):203-215

13. Smith ML, Auer RN, Siesjo BK 1984 The density and distribution of ischemic brain injury in the rat following 2-10 min of forebrain ischemia. Ann Neuropathol 64:319-332

14. Brown AW, Brierley JB 1971 Anoxic-ischaemic cell change in rat brain light microscopic and fine structural observations. J Neurol Sci 16:59-84

15. Siegal S 1956 Nonparametric Statistics for the Behavioural Sciences. McGrawHill Book Company, New York

16. Dimpfel W, Spuler M, Nickel B, Tibes U 1986 "Fingerprints" of central stimulatory drug effect by means of quantitative radioelectroencephalography in the rat (Tele-stereo-EEG). Neuropsychobiology 15:101-108

17. Ackryod M 1973 Digital filters, Computers in Medicine series. Butterworths, London

18. Gasser T, Bacher P, Mocks J 1982 Transformations towards the normal distribution of broad band spectral parameters of the EEG. Electroencephalogr Clin Neurophysiol 53:119-124

19. Hill A, Volpe JJ 1982 Hypoxic-ischemic brain injury in the newborn. Semin Perinatol 6(10):25-41

20. Brann AW 1986 Hypoxic ischemic encephalopathy (asphyxia). Pediatr Clin North Am 33(30):451-464

21. Volpe JJ, Herscovitch P, Perlman J, Kreusser K, Raiche M 1985 Positron emission tomography in the asphyxiated term newborn: parasagittal impairment of cerebral blood flow. Ann Neurol 17:287-296

22. Silverstein F, Buchanan K, Johnston M 1984 Pathogenesis of hypoxic-ischemic brain injury in a perinatal rodent model. Neurosci Lett 49:271-277

23. Brann AW, Myers RE 1975 Central nervous system findings in the newborn monkey following severe in utero partial asphyxia. Neurology 25:327-338

24. Graham DI 1977 Pathology of hypoxic brain damage in man. J Clin Pathol 30(11): $170-180$

25. Brierley JB, Brown AW, Excell BJ, Meldrum BS 1969 Brain damage in the Rhesus monkey from profound arterial hypotension. Brain Res 13:68-100

26. Vannuccci RC, Lyons D, Vasta F 1988 Regional cerebral blood flow during hypoxia-ischemia in immature rats. Stroke 19:245-250
27. Cavazzuti M, Duffy TE 1982 Regulation of local cerebral blood flow in normal and hypoxic newborn dogs. Ann Neurol 11:247-257

28. Laptook A, Stonestreet BS, Oh W 1982 The effects of different rates of plasmanate infusions upon brain blood flow after asphyxia and hypotension in newborn piglets. J Pediatr 100(5):791-796

29. Ashwal S, Dale PS, Longo LD 1984 Regional cerebral blood flow: studies in the fetal lamb during hypoxia, hypercapnia, acidosis, and hypotension. Pediatr Res 18:1309-1316

30. Behrman RE, Lees MH, Peterson EN, De Lannoy CW, Seeds AE 1970 Distribution of the circulation in the normal and asphyxiated fetal primate. Am J Obstet Gynecol 108(6):956-969

31. Hernandez MJ, Hawkins RA, Brennan RW, Vannucci RC, Helm BL, Bowman GS 1979 Redistribution of regional cerebral blood flow during neonatal asphyxia. Acta Neurol Scand 60(suppl 72):288-289

32. Larroche J-C 1984 Perinatal brain damage. In: Dams JH, Corsellis JA, Duchen LW (eds) Greenfields Neuropathology, 4th ed. Edward Arnold, London, 451-489

33. Auer RN, Siesjo B 1988 Biological differences between ischemia, hypoglycemia, and epilepsy. Ann Neurol 24:699-707

34. Andine P, Lehmann A, Ellren K, Wennberg E, Kjellmer I 1988 The excitatory amino acid antagonist kynurenic acid administered after hypoxic ischemia in neonatal rats offers neuroprotection. Neurosci Lett 90:208-212

35. Hattori H, Morin A, Schwartz P, Fukikamwa D, Wasterlain C 1989 Posthypoxic treatment with $\mathrm{Mk}-801$ reduces hypoxic-ischemic damage in the neonatal rat. Neurology 39:713-718

36. Stein D, Vannucci R 1988 Calcium accumulation during the evolution of hypoxic-ischemic brain damage in the immature rat. $\mathrm{J}$ Cereb Blood Flow Metab 8:834-842

37. Rosenberg A, Murdaugh E, White C 1989 The role of oxygen free radicals in postasphyxia cerebral hypoperfusion in newborn lambs. Ped Res 26(3):215219

38. Mitzdorf U 1985 Current source-density method and application in cat cerebral cortex: investigation of evoked potentials and EEG phenomena. Physiol Rev 65:37-100

39. Barth DS, Di S, Baumgartner C 1989 Laminar cortical interactions during epileptic spikes studied with principal component analysis and physiological modelling. Brain Res 484:13-35

40. Gloor P, Fariello R 1988 Generalized epilepsy: some of its cellular mechanisms differ from those of focal epilepsy. TINS 11(2):63-68

41. Nevander G, Ingvar M, Auer R, Siesjo BK 1985 Status epilepticus in welloxygenated rats causes neuronal necrosis. Ann Neurol 18:281-290

42. Sapolsky RM, Stein BA 1989 Status epilepticus-induced hippocampal damage is modulated by glucose availability. Neurosci Lett 97:157-162

43. Bronzino JD 1984 Quantitative analysis of the EEG-general concepts and animal studies. IEEE Trans Biomed Eng 31(12):850-856

44. Gevins AS, Schaffer RE 1980 A critical review of electroencephalographic (EEG) correlates of higher cortical functions. CRC Crit Rev Bioeng October:113-164 